\title{
Development and in vivo validation of tissue-engineered, small-diameter vascular grafts from decellularized aortae of fetal pigs and canine vascular endothelial cells
}

Xu Ma ${ }^{1 \dagger}$, Zhijuan $\mathrm{He}^{2+}$, Ling Li ${ }^{3}$, Guofeng Liư ${ }^{1 *}$, Qingchun $\mathrm{Li}^{1}$, Daping Yang ${ }^{1}$, Yingbo Zhang ${ }^{1}$ and Ning Li ${ }^{1}$

\begin{abstract}
Background: Tissue engineering has emerged as a promising alternative for small-diameter vascular grafts. The aim of this study was to determine the feasibility of using decellularized aortae of fetal pigs (DAFPs) to construct tissueengineered, small-diameter vascular grafts and to test the performance and application of DAFPs as vascular tissueengineered scaffolds in the canine arterial system.

Methods: DAFPs were prepared by continuous enzymatic digestion. Canine vascular endothelial cells (ECs) were seeded onto DAFPs in vitro and then the vascular grafts were cultured in a custom-designed vascular bioreactor system for 7 days of dynamic culture following 3 days of static culture. The grafts were then transplanted into the common carotid artery of the same seven dogs from which ECs had been derived (two grafts were prepared for each dog with one as a backup; therefore, a total of 14 tissue-engineered blood vessels were prepared). At 1, 3, and 6 months post-transplantation, ultrasonography and contrast-enhanced computed tomography (CT) were used to check the patency of the grafts. Additionally, vascular grafts were sampled for histological and electron microscopic examination.
\end{abstract}

Results: Tissue-engineered, small-diameter vascular grafts can be successfully constructed using DAFPs and canine vascular ECs. Ultrasonographic and CT test results confirmed that implanted vascular grafts displayed good patency with no obvious thrombi. Six months after implantation, the grafts had been remodeled and exhibited a similar structure to normal arteries. Immunohistochemical staining showed that cells had evenly infiltrated the tunica media and were identified as muscular fibroblasts. Scanning electron microscopy showed that the graft possessed a complete cell layer, and the internal cells of the graft were confirmed to be ECs by transmission electron microscopy.

Conclusions: Tissue-engineered, small-diameter vascular grafts constructed using DAFPs and canine vascular ECs can be successfully transplanted to replace the canine common carotid artery. This investigation potentially paves the way for solving a problem of considerable clinical need, i.e., the requirement for small-diameter vascular grafts.

Keywords: Vascular endothelial cells, Decellularized aortae of fetal pigs, Scaffold, Tissue-engineered small-diameter vascular grafts

\footnotetext{
* Correspondence: FennyL789@163.com

${ }^{\dagger}$ Equal contributors

${ }^{1}$ Department of Plastic Surgery, The Second Affiliated Hospital of Harbin

Medical University, 246 Xuefu Road, Nangang District, Harbin, Heilongjiang

150086, China

Full list of author information is available at the end of the article
} 


\section{Background}

Coronary artery and peripheral arterial diseases have high rates of mortality and morbidity and so represent a massive economic and clinical burden to healthcare worldwide [1]. The most promising approach to solving this vascular problem and thus reducing the morbidity associated with these diseases is the use of small-diameter $(<6 \mathrm{~mm})$ vascular grafts [2]. Although autologous vessels (e.g., saphenous veins) represent the gold standard grafts for small-diameter vessels, many patients do not have veins suitable for grafting [3]. Thus, there is a considerable clinical need for small-diameter vascular grafts.

Tissue engineering has emerged as a promising alternative for producing small-diameter vascular grafts [4]. Tissue engineering strategies consist of three main components: scaffolds that house the cells and support cellular growth and activity; seed cells, which preserve the specific function of the tissue; and a nurturing environment [5]. Scaffolds provide temporary or permanent support to damaged tissues, and scaffold materials can be generally divided into two categories: native biological materials and synthetic polymeric materials [6]. Compared with synthetic polymer-based scaffolds, natural polymers present a biologically active environment to cells and promote excellent cell adhesion and growth [7]. However, numerous studies have also reported on the poor mechanical properties of natural polymers [7-9]. Recently, decellularized tissue-engineered vascular grafts have been widely used as natural scaffolds to produce arterial conduits that provide ideal biomechanical properties and cell compatibility $[10,11]$. For instance, Böer et al. showed that intensified decellularization of equine carotid arteries generated highly suitable matrix scaffolds for vascular tissue engineering [12]. However, the in vivo application of tissue-engineered vascular grafts has not been widely investigated.

Recently, Liu et al. studied the mechanical properties of decellularized aortae of fetal pigs (DAFPs) and conducted an assessment of cell adhesion and compatibility by seeding with porcine aortic endothelial cells (ECs) and performing subdermal implantation in adult male Sprague Dawley rats [13]. Their results showed that DAFPs exhibited minimal calcification and exhibited almost no immunological reaction during the entire follow-up period [13]. In this study, small-diameter vascular grafts were constructed with DAFPs and by seeding with canine vascular ECs. These vascular grafts were then implanted into the same dogs from which ECs had been derived. The aim of this study was to determine the feasibility of using DAFPs to construct tissue-engineered small-diameter vascular grafts and to test the performance and application of DAFPs as tissue-engineered vascular scaffolds in the canine arterial system.

\section{Methods}

\section{Experimental animals}

Fetal pigs of 100-day gestational age were delivered by cesarean section. Adult mongrel dogs were used as both vascular EC donors and graft recipients. All animals received humane care in compliance with the Guide for Care and Use of Laboratory Animals published by the National Institutes of Health (NIH publication No. 85-23, revised 1996).

\section{Preparation of fetal pig aorta}

Pregnant sows were intravenously anesthetized with $1 \%$ pentobarbital sodium $(10 \mathrm{mg} / \mathrm{kg})$ and delivered by cesarean section. After removal of fetuses, sows were euthanized by excessive anesthesia. Fetal pigs with crown-rump lengths of $25-30 \mathrm{~cm}$ were selected and 5 - $\mathrm{cm}$ sections of aorta were excised under sterile conditions. These specimens werecryopreserved immediately transported to the laboratory with a warm ischemia time of $<30 \mathrm{~min}$ [14].

\section{Preparation of DAFPs}

Fetal pig aortae with an outer diameter of $4 \mathrm{~mm}$ and a length of $6 \mathrm{~cm}$ were selected. After removal of surrounding tissues under sterile condition, the blood vessels were washed with sterile saline several times to remove residual blood. DAFPs were prepared by continuous enzymatic digestion using trypsin, DNase, and RNase as previously described [15] with few modifications. Aortae were first digested with a solution containing $0.1 \%$ trypsin/0.02\% EDTA in phosphate-buffered saline (PBS) (without $\mathrm{Ca}^{2+}$ and $\mathrm{Mg}^{2+}$ ) for $36 \mathrm{~h}$ (all reagents from Sigma, St. Louis, Mo., USA), and the solution was changed every $12 \mathrm{~h}$. The aortae were then decellularized with $20 \mu \mathrm{g} / \mathrm{mL}$ RNase and $200 \mu \mathrm{g} / \mathrm{mL}$ DNase (Boehringer, Mannheim, Germany) for $4 \mathrm{~h}$ at $37{ }^{\circ} \mathrm{C}$ under a humidified atmosphere of $5 \% \mathrm{CO}_{2}$ and $95 \%$ air with constant gentle shaking. DAFPs were then washed with sterile PBS several times to remove the digestion residue. Following DAFP preparation, approximately $3 \mathrm{~mm}$ of the tissue at the end of each decellularized specimen was taken and cut into two semi-rings. Half of the tissue was examined following conventional hematoxylin-eosin (HE) staining, and the other half was used for DNA quantification [16]. Finally, DAFPs were subjected to vacuum freeze-drying and ethylene oxide sterilization.

\section{Culture and identification of canine vascular ECs}

Seven domestic dogs aged 6 months and weighing $25 \mathrm{~kg}$ were used. Intravenous administration of $1 \%$ pentobarbital sodium $(10 \mathrm{mg} / \mathrm{kg})$ was used for anesthesia. Approximately $10 \mathrm{~cm}$ of the left external jugular vein was excised under aseptic condition as previously described [17]. Primary vascular ECs were obtained by 
enzymatic digestion as previously described [18]. In brief, the outer membrane layer of the vessel was removed and the vessel was cut longitudinally to form a sheet. The intima layer was flattened on the culture dish. A solution of $0.2 \%$ collagenase A (Boehringer Mannheim, Germany) in PBS with $\mathrm{Ca}^{2+}$ and $\mathrm{Mg}^{2+}$ was injected beneath the inner membrane surface and subsequent digestion performed in an incubator for $15 \mathrm{~min}$. The digested EC suspension was collected and centrifuged at $1000 \mathrm{rpm}$ for $5 \mathrm{~min}$. The EC pellet was resuspended and cultured in medium 199 (GIBCO) supplemented with $10 \%$ fetal bovine serum, 100 units $/ \mathrm{mL}$ penicillin (Sigma), $100 \mathrm{mg} / \mathrm{mL}$ streptomycin (Sigma), $0.25 \mathrm{mg} / \mathrm{mL}$ amphotericin B (Sigma), $5 \mathrm{ng} / \mathrm{mL}$ endothelial growth factor (Boehringer Mannheim) and 1\% Lglutamine (Sigma). Cells were passaged using trypsin digestion and the fourth generation was used as seed cells (the number of vascular seed cells in the fourth generation was sufficient for seeding purposes, and ECs still possessed abundant proliferative capacity at this passage). Cells were confirmed to be vascular ECs by morphology as well as by immunohistochemistry and immunofluorescence to detect the endothelial marker von Willebrand factor (vWF) as previously described [19].

\section{Construction of tissue-engineered, small-diameter vascu- lar grafts}

Vacuum freeze-dried DAFP material was soaked in sterile PBS for $24 \mathrm{~h}$. Vascular ECs were seeded onto DAFPs by rotational precipitation. Briefly, ECs were trypsinized to form a cell suspension and the EC concentration was adjusted to $3 \times 10^{6}$ cells $/ \mathrm{mL}$. Both ends of DAFP tubular stents were clamped and the cell suspension was injected into the arterial lumen using a syringe. The arteries were then rotated $120^{\circ}$ after standing for $10 \mathrm{~min}$ and seeding was completed after a total rotation of $360^{\circ}$. The grafts were transferred to a vascular bioreactor system for 7 days of dynamic culture following 3 days of static culture. A vascular bioreactor system was designed and produced by our research group as depicted in Fig. 1. This bioreactor system was driven by a peristaltic pump [20] and specimens were placed in the processing chamber (Fig. 1b). The liquid flow in the system was gradually increased by adjusting the speed of the peristaltic pump so that the perfusion rate increased from 20 to $60 \mathrm{~mL} /$ min (the perfusion rate was $20 \mathrm{~mL} / \mathrm{min}$ on the first day of dynamic culture and increased by $10 \mathrm{~mL} / \mathrm{min}$ daily to $60 \mathrm{~mL} / \mathrm{min}$ on the fifth day of dynamic culture, at which point the perfusion rate was maintained at $60 \mathrm{~mL} / \mathrm{min}$ through to the seventh day). The static pressure due to height differences of the culture solutions was $10 \mathrm{mmHg}$, and the dynamic pressure generated by the peristaltic pump was $60 \mathrm{mmHg}$. After culture completion, the fixed ends (lacking ECs) were removed and then the grafts were used for surgical implantation into the same dogs from which ECs had been derived.

\section{Surgical implantation of vascular grafts}

The same seven dogs from which left external jugular veins were harvested to obtain ECs received general anesthesia. Routine preoperative preparation was followed and the right common carotid artery was

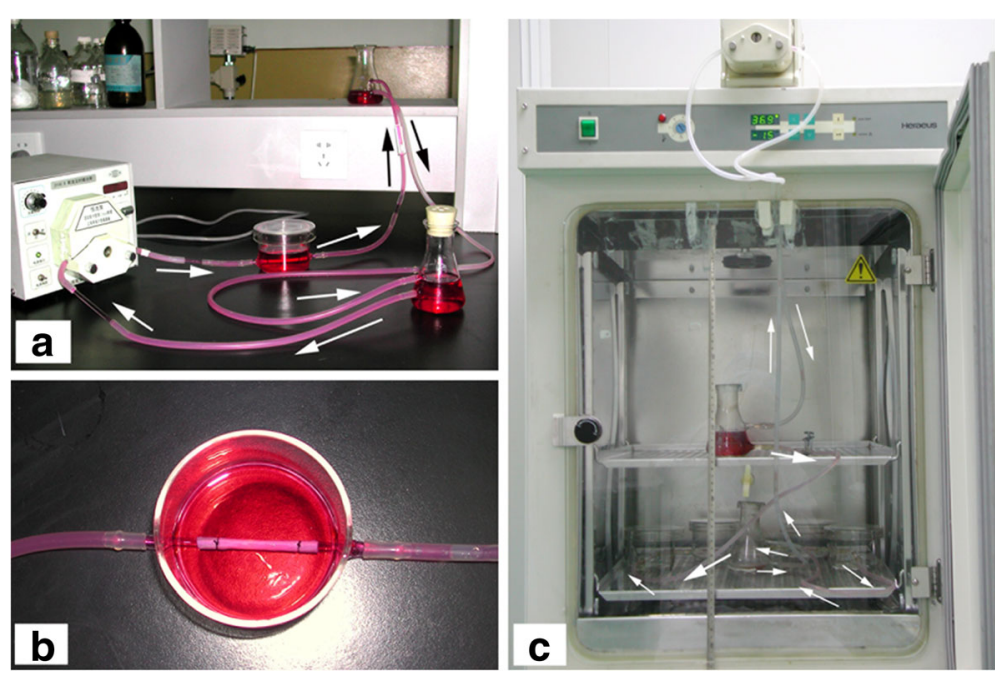

Fig. 1 A custom-designed and-produced vascular bioreactor system. $\mathbf{a}$, the design of the vascular bioreactor system. b, the processing chamber used for specimen fixation. c, operation of the dynamic vascular bioreactor system. The dynamic vascular bioreactor system was placed into a tissue culture incubator. The height difference between culture solutions was regulated to control the static pressure within the vascular grafts. A controlled peristaltic pump regulated the dynamic pressure within the vascular grafts and the flow rate variation of the culture solutions. The arrows show the operation of the dynamic vascular bioreactor system 
exposed. A location of the carotid artery with an external diameter of approximately $4 \mathrm{~mm}$ at diastole was selected as the site for implantation of the tissueengineered vascular grafts. Vascular clamps were placed on both sides of the selected position, and the artery (4 $\mathrm{mm}$ in diameter) was transected. The tissueengineered vascular grafts were used to bridge the common carotid artery using microsurgical techniques. The incisions were closed, and routine intramuscular injection of heparin as well as intravenous injection of antibiotics were applied postoperatively. Doppler ultrasonography was conducted at 1, 3, and 6 months and contrast-enhanced CT at 6 months, following implantation. Vascular grafts were sampled for histological and electron microscopic examination after the dogs were sacrificed at 6 months post-implantation.

\section{Doppler ultrasonography and enhanced $\mathrm{CT}$ examination}

All experimental animals received general anesthesia prior to each procedure and neck skin preparation prior to ultrasonic examination. Bilateral common carotid artery ultrasound was performed using a Doppler ultrasound device. Animals were injected with contrast medium prior to three-dimensional CT angiography.

\section{HE staining}

DAFPs and sampled vascular grafts were fixed in 10\% neutral-buffered formalin solution, embedded in paraffin, transversely sectioned $(5 \mu \mathrm{m})$ and stained using $\mathrm{HE}$ for histological assessment of general morphology.

\section{Electron microscopy}

Specimen surface ultrastructure was examined by scanning electron microscopy (SEM). Briefly, specimens were sequentially fixed in $1 \%(\mathrm{v} / \mathrm{v})$ buffered glutaraldehyde and $0.1 \%(\mathrm{v} / \mathrm{v})$ buffered formaldehyde for 1 and $24 \mathrm{~h}$, respectively, dehydrated with a graded ethanol series, and dried. Dried samples were mounted on aluminum chucks and sputter-coated with gold (Cressington 108; Cressington Scientific Instruments, PA, USA). An S$3400 \mathrm{~N}$ scanning electron microscope (Hitachi, Tokyo, Japan) was used for sample examination.
For transmission electron microscopy (TEM), specimens were fixed in $2.5 \%$ glutaraldehyde solution, rinsed with $0.1 \mathrm{M}$ phosphate buffer, and then fixed in $1 \%$ osmic acid for $2 \mathrm{~h}$. Subsequent rinsing in doubledistilled water was followed by dehydration in a graded series of water-acetone solution. Specimens were then impregnated with Epon 812 resin, embedded, and polymerized. Semi-thin sections were counterstained with azure II and basic fuchsin and examined with light microscopy to determine orientation. Ultra-thin sections were stained with uranyl acetate and lead citrate and then examined with a Zeiss EM10 electron microscope (Zeiss, Oberkochen, Germany).

\section{Results}

\section{Identification of canine vascular ECs and morphology of DAFPs}

Immunohistochemistry and immunofluorescence showed positive vWF staining in most cells (Fig. 2).

Histological staining of fetal porcine aortae revealed a typical three-layer structure of the arteries (Fig. 3A-a), and SEM demonstrated a complete layer of ECs with a cobblestone phenotype (Fig. 3B-a, b). The DNA content of DAFPs was $<0.1 \%$. Histological staining of DAFPs showed that the extracellular matrix remained intact; however, no nuclei or intact cells were present (Fig. 3A-b). In addition, SEM examination showed that after decellularization, endogenous ECs were completely removed and the structure of the inner elastic membrane was clearly visible (Fig. 3B-c, d).

\section{Characterization of tissue-engineered, small-diameter vas- cular grafts}

After 1 week of dynamic culture in the custom-made dynamic vascular bioreactor system, vascular grafts were successfully constructed using DAFPs and canine vascular ECs (Fig. 4). The vascular grafts possessed a complete, intact EC layer. Histological findings showed that a continuous cell layer was present on the inner surface of the grafts (Fig. 3A-c), and SEM revealed that ECs were tightly connected, forming a continuous cell layer that completely covered the inner elastic membrane (Fig. 3B-e, f).

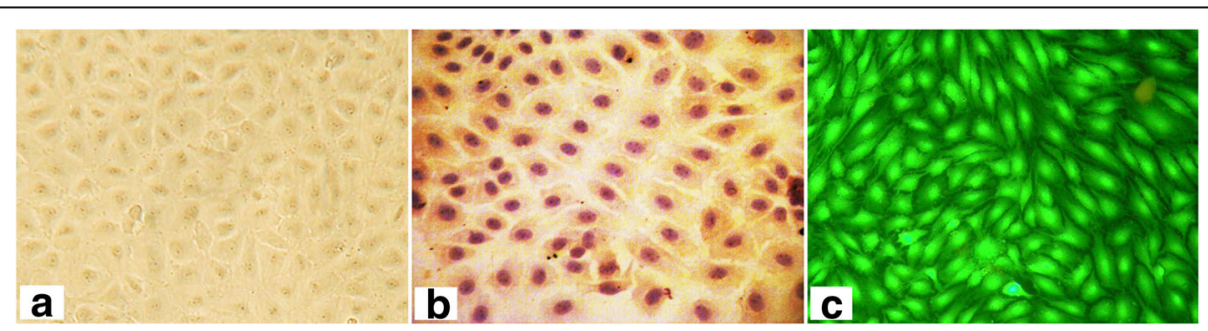

Fig. 2 Culture and identification of canine vascular endothelial cells (ECs). a optical microscopy image of ECs; $\mathbf{b}$ immunohistochemical staining for von Willebrand factor (VWF); c immunofluorescence of VWF. Most cells were VWF-positive 
A

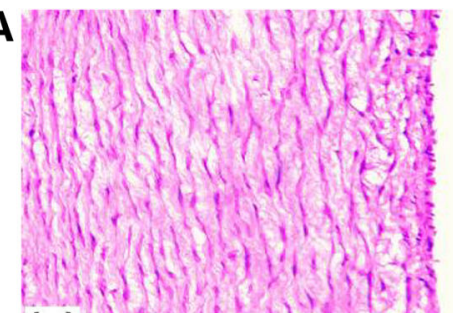

(a)

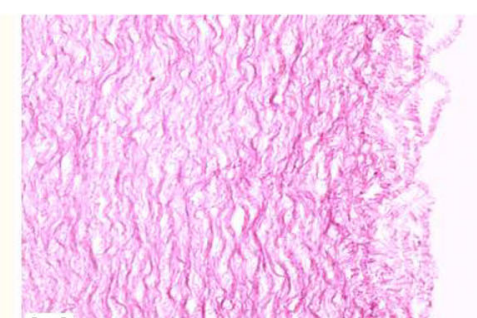

(b)
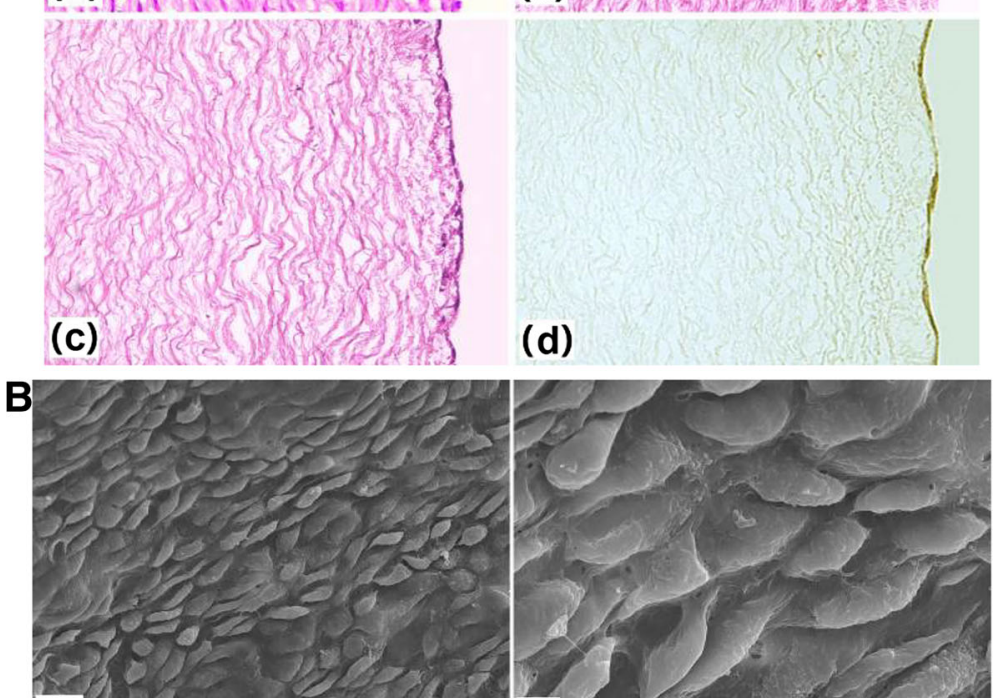

(a)
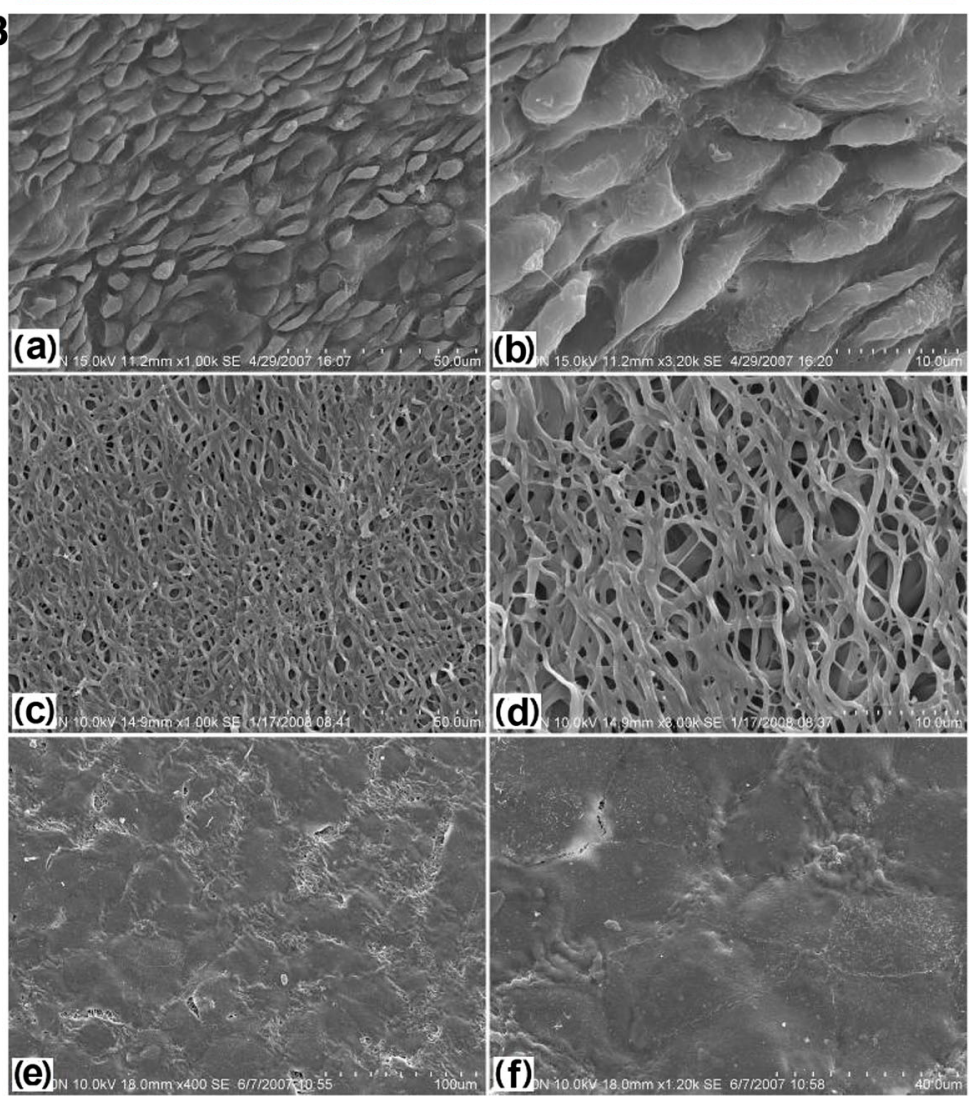

Fig. 3 Histological and immunohistochemical staining and scanning electron microscopy of specimens. A: a, histological staining of fetal pig aorta; $\mathbf{b}$ : histological staining of decellularized aortae of fetal pigs (DAFPs); $\mathbf{c}$ : histological staining of tissue-engineered vascular grafts with an EC layer; $\mathbf{d}$ : immunohistochemical staining of ECs of vascular grafts. B: a: fetal pig aortic EC layer at low magnification; $\mathbf{b}$ : fetal pig aortic EC layer at high magnification; $\mathbf{c}$ : the inner elastic membrane of DAFPs at low magnification; $\mathbf{d}$ : the inner elastic membrane of DAFPs at high magnification; e: the EC layer of tissue-engineered vascular grafts at low magnification; $\mathbf{f}$ : the EC layer of tissue-engineered vascular grafts at high magnification

\section{Implantation and evaluation}

Seven dogs were numbered and all were subjected to extensive postoperative evaluation (Table 1). Vascular diameter of the grafts matched that of the common carotid artery into which they had been implanted (Fig. 4). Following implantation, vascular grafts exhibited good patency and no obvious thrombi were found attached to the vascular wall, as assessed by Doppler 


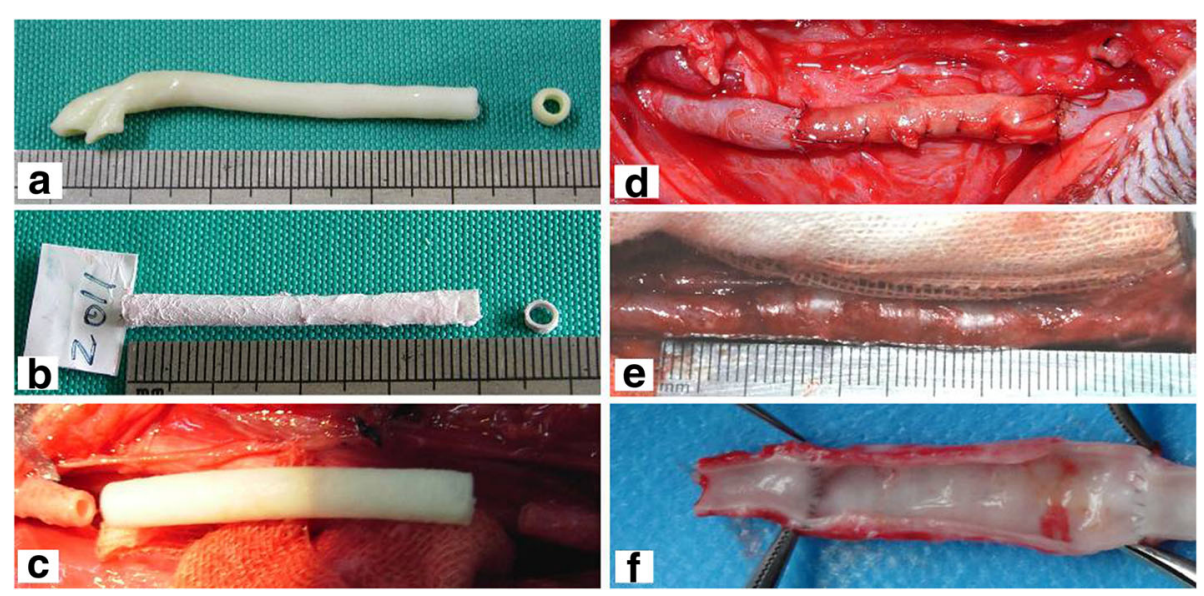

Fig. 4 General morphology of specimens. a general morphology of fetal pig aorta; $\mathbf{b}$ general morphology of vacuum freeze-dried DAFPs; $\mathbf{c}$ tissue-engineered vascular grafts after dynamic seeding of ECs; $\mathbf{d}$ the implantation of tissue-engineered vascular grafts in dogs; e general morphology of sampled vascular grafts at 6 months post-implantation; $\mathbf{f}$ the inner morphology of sampled vascular grafts at

6 months post-implantation

ultrasound and enhanced CT examination (Fig. 5). Six months after implantation, the grafts showed no obvious stenosis and expansion. Additionally, dynamic Doppler sonography revealed good graft compliance, and vascular grafts underwent spontaneous rhythmic vasodilation and contraction in synchrony with heartbeat.

Sampling results at 6 months post-transplantation showed that the tissue-engineered vascular grafts had smooth surface and no thrombi. As depicted in Fig. 6, histological staining showed that the grafts had been remodeled within the animals, and a continuous inner cell layer was identified. The tunica media was structurally dense and similar to natural arterial structure, and cells had evenly infiltrated and were identified as muscular fibroblasts by immunohistochemistry (smooth muscle actin expression was used as a classical marker for myofibroblasts). In addition, TEM examination of the inner cells showed that their surfaces were rich in finger, spherical, and villous protrusions and that they contained abundant cytoplasmic organelles, indicating that they were indeed ECs (Fig. 7). Moreover, WeibelPalade bodies, which are membrane-enclosed rodshaped organelles specifically found in ECs, were also identified.

\section{Discussion}

Extracellular matrix (ECM) scaffolds for vascular tissue engineering have mainly been derived from decellularized vascular matrix and decellularized small intestinal submucosa $[21,22]$. Suitably decellularized blood vessels have the ideal shape and they possess biomechanical properties particularly suited for use as vascular grafts [23]. Li et al. have demonstrated that due to its low immunogenicity and optimal properties, decellularized fetal porcine vascular tissue could be used for tissueengineered, small-diameter vascular grafts and as a potential alternative to xenogeneic transplantation [24]. Taking into account these studies, we hypothesized that

Table 1 Extensive evaluation of seven dogs at 6 months post-implantation of tissue-engineered vascular grafts

\begin{tabular}{|c|c|c|c|c|c|}
\hline Number & Gross observations & Histological staining & $\begin{array}{l}\text { Color Doppler ultrasonography } \\
\text { and three-dimensional CT }\end{array}$ & $\begin{array}{l}\text { Scanning electron } \\
\text { microscopy }\end{array}$ & $\begin{array}{l}\text { Transmission electron } \\
\text { microscopy }\end{array}$ \\
\hline 1 & $\begin{array}{l}\text { No obvious expansion; } \\
\text { smooth surface without } \\
\text { thrombi when sampled }\end{array}$ & $\begin{array}{l}\text { Similar to natural arterial } \\
\text { structure; a continuous } \\
\text { cell inner layer; dense } \\
\text { tunica media }\end{array}$ & $\begin{array}{l}\text { Good patency; no obvious } \\
\text { thrombi; no obvious stenosis } \\
\text { and expansion }\end{array}$ & $\begin{array}{l}\text { Continuous endothelial } \\
\text { cell layer; tight cell } \\
\text { junctions }\end{array}$ & $\begin{array}{l}\text { Confirmation of the } \\
\text { continuous endothelial cell } \\
\text { layer; identification of } \\
\text { Weibel-Palade bodies }\end{array}$ \\
\hline 2 & $\sqrt{ }$ & $\sqrt{ }$ & $\sqrt{ }$ & $\sqrt{ }$ & $\sqrt{ }$ \\
\hline 3 & $\sqrt{ }$ & $\sqrt{ }$ & $\sqrt{ }$ & $\sqrt{ }$ & $\sqrt{ }$ \\
\hline 4 & $\sqrt{ }$ & $\sqrt{ }$ & $\sqrt{ }$ & $\sqrt{ }$ & $\sqrt{ }$ \\
\hline 5 & $\sqrt{ }$ & $\sqrt{ }$ & $\sqrt{ }$ & $\sqrt{ }$ & $\sqrt{ }$ \\
\hline 6 & $\sqrt{ }$ & $\sqrt{ }$ & $\sqrt{ }$ & $\sqrt{ }$ & $\sqrt{ }$ \\
\hline 7 & $\sqrt{ }$ & $\sqrt{ }$ & $\sqrt{ }$ & $\sqrt{ }$ & $\sqrt{ }$ \\
\hline
\end{tabular}

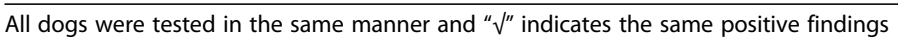



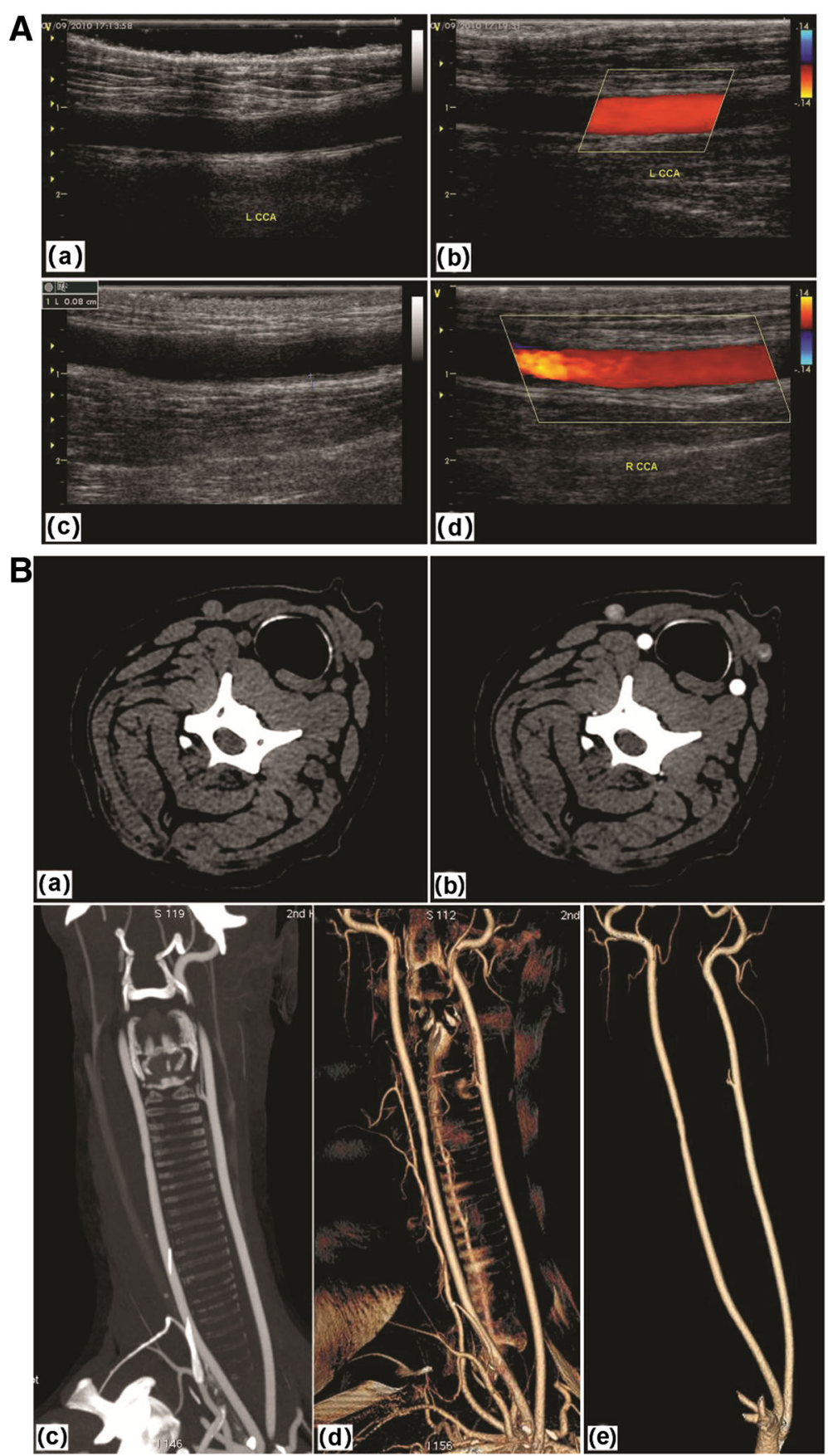

Fig. 5 Color Doppler ultrasonography and three-dimensional CT detection after the implantation of tissue-engineered vascular grafts into canine common carotid arteries. A: $\mathbf{a}$ and $\mathbf{b}$, Color Doppler ultrasonography at 3 months post-implantation; $\mathbf{c}$ and $\mathbf{d}, 6$ months post-implantation. B, three-dimensional CT detection at 6 months post-implantation. $\mathbf{a}$ and $\mathbf{b}$ are horizontal images; $\mathbf{c}$ is a coronal plane image; $\mathbf{d}$ and $\mathbf{e}$ are three-dimensional images

DAFPs could be used as a vascular tissue-engineered scaffold in the canine arterial system.

ECs seeded at the blood interface can prevent vascular grafts from being directly exposed to the bloodstream, consequently preventing thrombosis on the grafts, thus increasing their patency [25]. Cell- seeding methods include static seeding with biological glues and direct seeding [26]. Dynamic seeding can increase both cell-seeding efficiency and penetration of the scaffold [26]. In this study, a custom-designed and -produced vascular bioreactor system was used for dynamic seeding. This vascular bioreactor system 


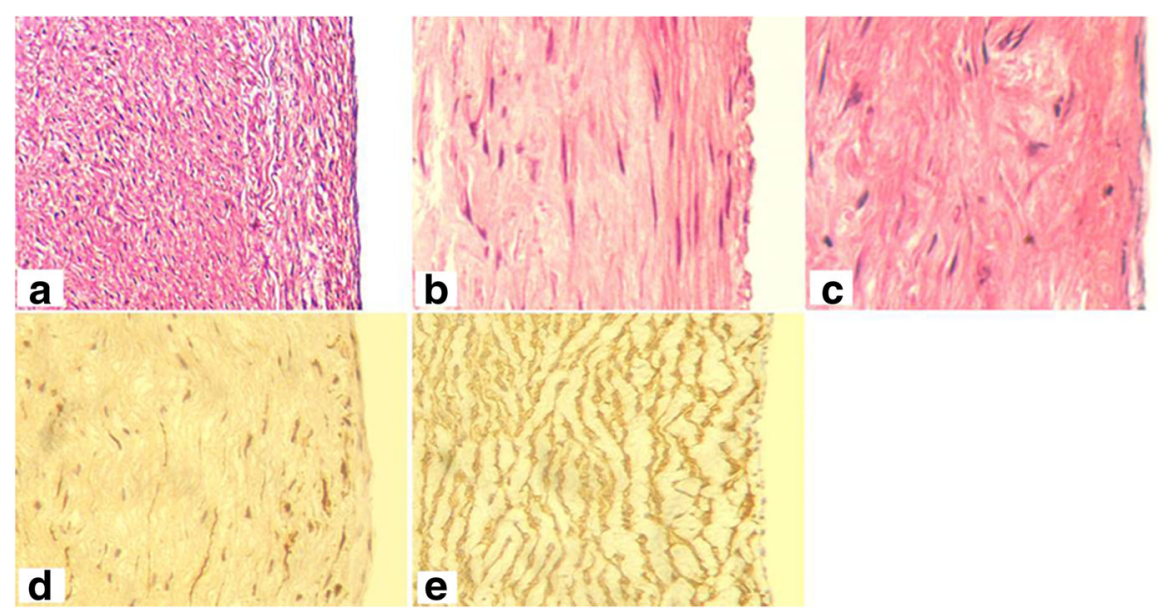

Fig. 6 Histological staining of tissue-engineered vascular grafts after implantation. $\mathbf{a}$, $\mathbf{b}$, and $\mathbf{c}$, Hematoxylin-eosin staining of tissue-engineered vascular grafts at 6 months post-implantation; $\mathbf{d}$ smooth muscle actin (SMA) immunohistochemical staining of vascular grafts; e SMA immunohistochemical staining of fetal pig aorta as a positive control

can simulate the internal vascular mechanical environment, promote adhesion and proliferation of ECs, and prevent seeded ECs from washing away after transplantation into the arterial system. The results of the present study showed that dynamic seeding caused ECs to tightly attach to DAFPs.

ECs and smooth muscle cells are the main cellular components of the vasculature [27]. Vascular smooth muscle cells in the tunica media have important functional roles, for instance, regulation of vascular diameter, increase of vascular compliance, and secretion of ECM to affect the function of ECs [28]. Generating a functional smooth muscle layer is therefore important for successful vascular tissue engineering. A matching level of compliance between tissue-engineered, smalldiameter vascular grafts and recipient vessels determines the long-term patency of blood vessels [29]. If a compliance mismatch occurs, fluid mechanical effects, such as the hydrodynamic shear stress of blood flow, result in graft wall thickening or expansion and formation of graft occlusions or aneurysms, ultimately leading to the failure of the implant [30].

However, the native architecture and low porosity of decellularized vessels have impeded efforts to seed smooth muscle layer into tissue-engineered blood vessels [31]. We also failed to seed smooth muscle cells into DAFPs due to the relatively compact structure of decellularized vessel matrix. Our laboratory is exploring effective methods for seeding smooth muscle cells into the acellular vascular matrix in vitro and trying to improve seeding efficiency using multi-needle, microneedle injection. Thus, in this study, tissue-engineered DAFP scaffolds were only seeded with ECs. We found that the vascular grafts we constructed in this study possessed a complete EC layer, indicating that our dynamic vascular bioreactor system meets the requirements of dynamic seeding of ECs.

We tried a variety of methods to label ECs in vitro to track seeded cells; however, our results were unsatisfactory and so cell-tracking experiments were not performed. We also implanted vascular grafts that had not been seeded with ECs in vitro, and this experiment is still ongoing. This ongoing investigation indicates that the patency of vascular grafts without seeded ECs is much lower (roughly no more than 60\%) than those containing seeded ECs as described here (data not shown). The presence of an EC layer was confirmed in the vicinity of the anastomotic stoma of unobstructed vascular grafts, but the EC layer was notably absent in the middle of the grafts, indicating that ECs were migrating along the grafts from both sides of the normal blood vessel. Thus, it seems likely that in vitro seeded ECs in this study were involved in the reconstruction of the EC layer of vascular grafts. Taken together, it can be deduced that there were three sources of ECs in the inner layers of the vascular grafts: in vitro seeded ECs; normal vascular ECs migrating from both ends of the graft; and endothelial progenitor cells deposited by the blood.

The diameter of the tissue-engineered blood vessels constructed using DAFPs matched that of the canine common carotid artery. The implanted tissue vascular grafts exhibited good patency, and no obvious thrombi were found attached to the vascular walls by Doppler ultrasound and enhanced CT examination.. Taken together, our results indicated that these tissueengineered blood vessels containing intact EC layers but no smooth muscle cell layers functioned well and were remodeled in vivo. 

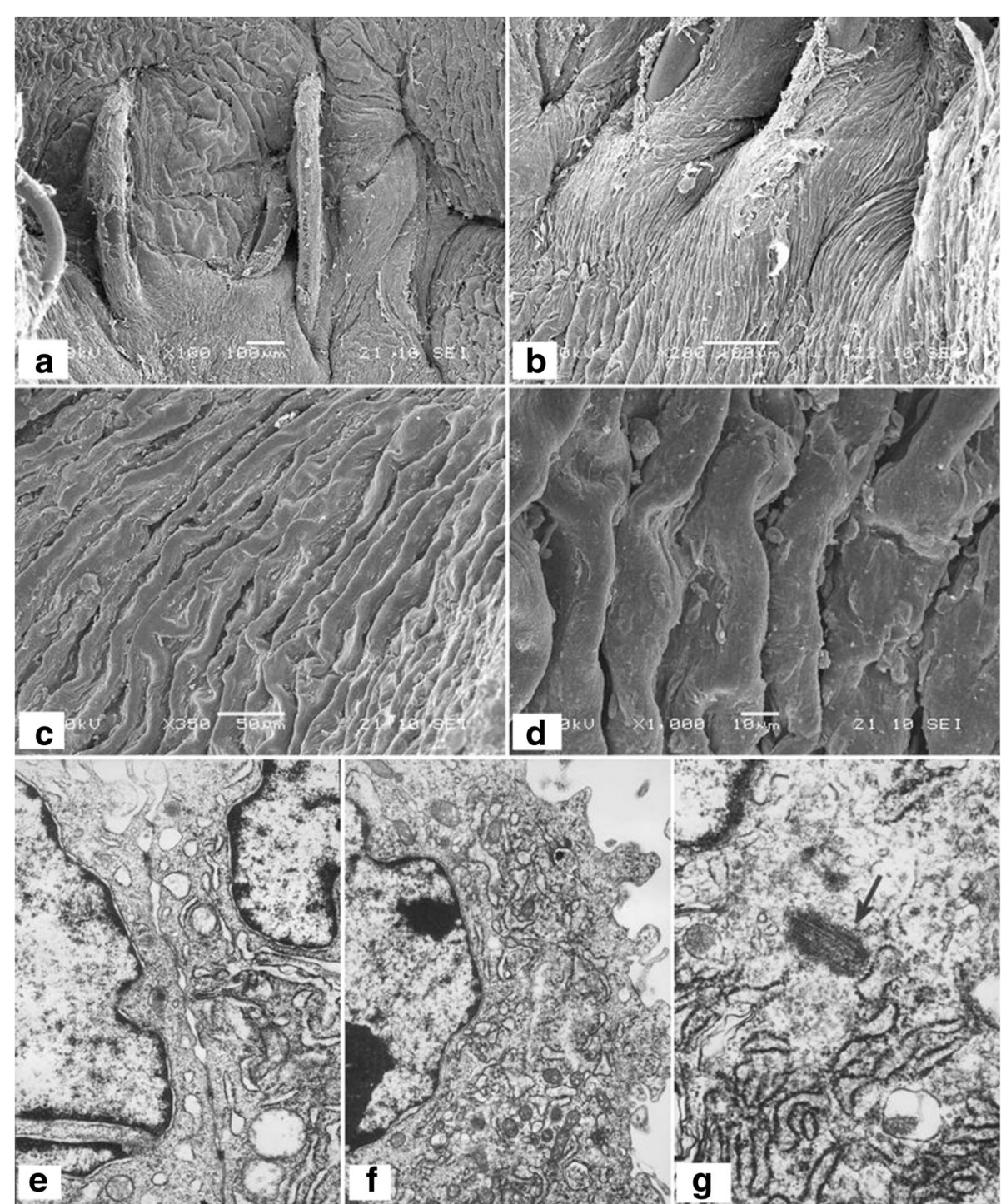

Fig. 7 Electron microscopy of tissue-engineered vascular grafts at 6 months post-implantation. a-d, the inner surface of vascular grafts by scanning electron microscopy; e, close connections between ECs were identified by transmission electron microscopy (TEM). $\mathbf{f}$, the cell cytoplasm was rich in active organelles identified by TEM. $\mathbf{g}$ specific structures of ECs as seen at high magnification by TEM

In this study, we examined the feasibility of using DAFPs as a heterologous biomaterial. The ultimate goal of this work is to apply this technique to clinical practice. Following further improvements and refinement of the preparation method, vascular ECs from human patients could be seeded onto this heterologous scaffold material and cultured in vitro prior to implantation back into the cell donor. However, it is clear that much research must be conducted before this technology can be applied to humans. For example, the source of vascular ECs must be the recipient of vascular grafts to avoid transplant rejection [32]. However, obtaining adult ECs from recipients is not necessarily an ideal method because of the limited number of ECs that can be acquired and the adverse effects on the recipient of additional surgical trauma. Thus, the ideal source of seed cells for tissue-engineered vascular grafts is in vitro culture and induced differentiation of bone marrow stromal stem cells or circulating stem cells from the recipient.

There are many advantages of using pigs as heterologous organ donors in xenotransplantation research [33, 34]. Fetal pig was selected as the source of a tissue-engineered vascular scaffold in this study was selected. A more standardized DAFP material and convenient method of acquisition of autologous vascular seed cells in the future may make it easier to prepare tissue-engineered vascular grafts that have similar histological structures and physiological functions to human 
blood vessels. This investigation potentially paves the way to addressing the considerable clinical need for small-diameter vascular grafts. However, several limitations of our study should also be considered. First, the observation time was relatively short and a longer postoperative follow-up period would be desirable. Second, a control arm lacking EC seeding has not been reported here but is currently underway. Finally, the vascular bioreactor system in this study needs to be improved to better simulate the in vivo vascular mechanics of the arterial system and to improve culture efficiency of the grafts.

\section{Conclusions}

Tissue-engineered, small-diameter vascular grafts with an intact EC layer can be successfully constructed using DAFPs. These tissue-engineered blood vessels can be transplanted to replace the canine common carotid artery. Additionally, the grafts are structurally and functionally similar to normal artery after remodeling in vivo in animals. Therefore, DAFPs hold the potential for use in constructing tissue-engineered, small-diameter vascular grafts.

\section{Abbreviations}

DAFP: Decellularized aorta of fetal pigs; ECM: Extracellular matrix; ECs: Endothelial cells; HE: Hematoxylin and eosin; SEM: Scanning electron microscopy; SMA: Smooth muscle actin; TEM: Transmission electron microscopy; vWF: von Willebrand factor; W-P: Weibel-Palade

\section{Acknowledgements}

Not applicable.

\section{Funding}

None.

\section{Availability of data and materials}

Not applicable. This study was only the primary research, and further study has been in progress.

\section{Authors' contributions \\ $\mathrm{XM}$ and $\mathrm{ZH}$ carried out the Conception and design of the research, participated in the Acquisition of data and drafted the manuscript. $L L$ and GL carried out the Analysis and interpretation of data. QL and DY participated in the Statistical analysis. $Y Z$ and Ni participated in the design of the study and performed the statistical analysis. XM and $\mathrm{ZH}$ conceived of the study, and participated in its design and coordination and helped to draft the manuscript. All authors read and approved the final manuscript.}

\section{Ethics approval}

This study was approved by Ethics Committee of the Second Affiliated Hospital of Harbin Medical University, the First Affiliated Hospital of Harbin Medical University,

\section{Consent for publication}

Not applicable.

\section{Competing interests}

The authors declare that they have no competing interests.

\section{Publisher's Note}

Springer Nature remains neutral with regard to jurisdictional claims in published maps and institutional affiliations.

\section{Author details}

'Department of Plastic Surgery, The Second Affiliated Hospital of Harbin Medical University, 246 Xuefu Road, Nangang District, Harbin, Heilongjiang 150086, China. ${ }^{2}$ Department of Obstetrics and Gynecology, The First Affiliated Hospital of Harbin Medical University, 23 Youzheng Street, Nangang District, Harbin, Heilongjiang 150086, China. ${ }^{3}$ Department of Cardiology, The Second Affiliated Hospital of Harbin Medical University, 246 Xuefu Road, Nangang District, Harbin, Heilongjiang 150086, China.

Received: 25 May 2017 Accepted: 6 November 2017

Published online: 25 November 2017

\section{References}

1. Kullo IJ, Rooke TW. Peripheral artery disease. N Engl J Med. 2016;374:861-71.

2. Adipurnama I, Yang MC, Ciach T, Butruk-Raszeja B. Surface modification and endothelialization of polyurethane for vascular tissue engineering applications: a review. Biomater Sci. 2016;5:22-37.

3. Gui L, Niklason LE. Vascular tissue engineering: building Perfusable vasculature for implantation. Curr Opin Chem Eng. 2014;3:68-74.

4. Wang W, Hu J, He C, Nie W, Feng W, Qiu K, et al. Heparinized PLLA/PLCL nanofibrous scaffold for potential engineering of small-diameter blood vessel: tunable elasticity and anticoagulation property. J Biomed Mater Res A. 2015;103:1784-97.

5. Grace NGJ, Soojung L, Robert BJ, Hwa JY, Eun YJ, Mi NB, et al. Trends in tissue engineering for blood vessels. J Biomed Biotechnol. 2012;2012: 956345.

6. Tibbitt MW, Rodell CB, Burdick JA, Anseth KS. Progress in material design for biomedical applications. Proc Natl Acad Sci U S A. 2015;112:14444-51.

7. O'Brien FJ. Biomaterials \& scaffolds for tissue engineering. Mater Today. 2011;14:88-95.

8. Meng ZX, Wang YS, Ma C, Zheng W, Li L, Zheng YF. Electrospinning of PLGA/gelatin randomly-oriented and aligned nanofibers as potential scaffold in tissue engineering. Mater Sci Eng C. 2010;30:1204-10.

9. Zhao W, Jin X, Cong Y, Liu Y, Fu J. Degradable natural polymer hydrogels for articular cartilage tissue engineering. J Chem Technol Biotechnol. 2013; 88:327-39.

10. Mcfetridge PS, Daniel JW, Bodamyali T, Horrocks M, Chaudhuri JB. Preparation of porcine carotid arteries for vascular tissue engineering applications. J Biomed Mater Res A. 2004;70A:224-34.

11. Lopez-Ruiz E, Venkateswaran S, Peran M, Jimenez G, Pernagallo S, DiazMochon JJ, et al. Poly(ethylmethacrylate-co-diethylaminoethyl acrylate) coating improves endothelial re-population, bio-mechanical and antithrombogenic properties of decellularized carotid arteries for blood vessel replacement. Sci Rep. 2017;7:017-00294.

12. Böer U, Hurtadoaguilar LG, Klingenberg M, Lau S, Jockenhoevel S, Haverich A, et al. Effect of intensified Decellularization of equine carotid arteries on scaffold biomechanics and Cytotoxicity. Ann Biomed Eng. 2015:49:2630-41.

13. Liu GF, He ZJ, Yang DP, Han XF, Guo TF, Hao CG, et al. Decellularized aorta of fetal pigs as a potential scaffold for small diameter tissue engineered vascular graft. Chin Med J. 2008;121:1398-406.

14. Abt PL, Praestgaard J, West S, Hasz R. Donor hemodynamic profile presages graft survival in donation after cardiac death liver transplantation. Liver Transpl. 2014;20:165-72.

15. Liao J, Joyce EM, Sacks MS. Effects of decellularization on the mechanical and structural properties of the porcine aortic valve leaflet. Biomaterials. 2008;29:1065-74.

16. Choi YC, Choi JS, Kim BS, Kim JD, Yoon HI, Cho YW. Decellularized extracellular matrix derived from porcine adipose tissue as a xenogeneic biomaterial for tissue engineering. Tissue Eng Part C Methods. 2012;18:866-76.

17. Falk J, Townsend LE, Vogel LM, Boyer M, Olt S, Wease GL, et al. Improved adherence of genetically modified endothelial cells to small-diameter expanded polytetrafluoroethylene grafts in a canine model. J Vasc Surg. 1998:27:902-9.

18. Aper T, Teebken O, Steinhoff G, Haverich A. Use of a fibrin preparation in the engineering of a vascular graft model. Eur J Vasc Endovasc Surg. 2004; 28:296-302.

19. Pratumvinit B, Reesukumal K, Janebodin K, leronimakis N, Reyes M. Isolation, characterization, and transplantation of cardiac endothelial cells. Biomed Res Int. 2013;2013:359412. 
20. Xu J, Ge H, Zhou X, Yang D, Guo T, He J, et al. Tissue-engineered vessel strengthens quickly under physiological deformation: application of a new perfusion bioreactor with machine vision. J Vasc Res. 2005;42:503-8.

21. Badylak SF, Freytes DO, Gilbert TW. Extracellular matrix as a biological scaffold material: structure and function. Acta Biomater. 2009;5:1-13.

22. Cleary MA, Geiger E, Grady C, Best C, Naito Y, Breuer C. Vascular tissue engineering: the next generation. Trends Mol Med. 2012;18:394-404.

23. Peng H-F, Liu JY, Andreadis ST, Swartz DD. Hair follicle-derived smooth muscle cells and small intestinal submucosa for engineering mechanically robust and vasoreactive vascular media. Tissue Eng A. 2011;17:981-90.

24. Li Q, Huang C, Xu Z, Liu G, Liu Y, Xiao Z, et al. The fetal porcine aorta and mesenteric acellular matrix as small-caliber tissue engineering vessels and microvasculature scaffold. Aesthet Plast Surg. 2013;37:822-32.

25. Dudash LA, Kligman F, Sarett SM, Kottke-Marchant K, Marchant RE. Endothelial cell attachment and shear response on biomimetic polymercoated vascular grafts. J Biomed Mater Res A. 2012;100:2204-10.

26. Villalona GA, Udelsman B, Duncan DR, McGillicuddy E, Sawh-Martinez RF, Hibino N, et al. Cell-seeding techniques in vascular tissue engineering. Tissue Eng B Rev. 2010;16:341-50.

27. Zhou R, Zhu L, Fu S, Qian Y, Wang D, Wang C. Small diameter blood vessels bioengineered from human adipose-derived stem cells. Sci Rep. 2016;6: 35422.

28. Qiu J, Zheng Y, Hu J, Liao D, Gregersen H, Deng X, et al. Biomechanical regulation of vascular smooth muscle cell functions: from in vitro to in vivo understanding. J R Soc Interface. 2014;11:20130852.

29. Fernandez CE, Achneck HE, Reichert WM, Truskey GA. Biological and engineering design considerations for vascular tissue engineered blood vessels (TEBVs). Curr Opin Chem Eng. 2014;3:83-90.

30. Stewart SF, Lyman DJ. Effects of a vascular graft/natural artery compliance mismatch on pulsatile flow. J Biomech. 1992;25:297-310.

31. Yazdani SK, Watts B, Machingal M, Jarajapu YP, Van Dyke ME, Christ GJ. Smooth muscle cell seeding of decellularized scaffolds: the importance of bioreactor preconditioning to development of a more native architecture for tissue-engineered blood vessels. Tissue Eng A. 2009;15:827-40.

32. Hopkinson C, Romano V, Kaye R, Steger B, Stewart R, Tsagkataki M, et al. The influence of donor and recipient gender incompatibility on corneal transplant rejection and failure. Am J Transplant. 2017;17:210-7.

33. Ekser B, Cooper DK, Tector AJ. The need for xenotransplantation as a source of organs and cells for clinical transplantation. Int J Surg. 2015;23:199-204.

34. Cooper DK, Ekser B, Ramsoondar J, Phelps C, Ayares D. The role of genetically engineered pigs in xenotransplantation research. J Pathol. 2016; 238:288-99.

\section{Submit your next manuscript to BioMed Central and we will help you at every step:}

- We accept pre-submission inquiries

- Our selector tool helps you to find the most relevant journal

- We provide round the clock customer support

- Convenient online submission

- Thorough peer review

- Inclusion in PubMed and all major indexing services

- Maximum visibility for your research

Submit your manuscript at www.biomedcentral.com/submit

) Biomed Central 